\title{
Occurrence of C-Terminal Residue Exclusion in Peptide Fragmentation by ESI and MALDI Tandem Mass Spectrometry
}

\author{
Mathieu Dupré, Sonia Cantel, Jean Martinez, Christine Enjalbal
}

Institut des Biomolécules Max Mousseron (IBMM), UMR 5247, Bâtiment Chimie (17), Université Montpellier 2, Universités Montpellier 1 et 2 - CNRS, Place Eugène Bataillon, 34095 Montpellier Cedex 5, France

\begin{abstract}
By screening a data set of 392 synthetic peptides MS/MS spectra, we found that a known C-terminal rearrangement was unexpectedly frequently occurring from monoprotonated molecular ions in both ESI and MALDI tandem mass spectrometry upon low and high energy collision activated dissociations with QqTOF and TOF/TOF mass analyzer configuration, respectively. Any residue localized at the C-terminal carboxylic acid end, even a basic one, was lost, provided that a basic amino acid such arginine and to a lesser extent histidine and lysine was present in the sequence leading to a fragment ion, usually depicted as $\left(\mathrm{b}_{n-1}+\mathrm{H}_{2} \mathrm{O}\right)$ ion, corresponding to a shortened nonscrambled peptide chain. Far from being an epiphenomenon, such a residue exclusion from the peptide chain C-terminal extremity gave a fragment ion that was the base peak of the MS/MS spectrum in certain cases. Within the frame of the mobile proton model, the ionizing proton being sequestered onto the basic amino acid side chain, it is known that the charge directed fragmentation mechanism involved the C-terminal carboxylic acid function forming an anhydride intermediate structure. The same mechanism was also demonstrated from cationized peptides. To confirm such assessment, we have prepared some of the peptides that displayed such C-terminal residue exclusion as a C-terminal backbone amide. As expected in this peptide amide series, the production of truncated chains was completely suppressed. Besides, multiply charged molecular ions of all peptides recorded in ESI mass spectrometry did not undergo such fragmentation validating that any mobile ionizing proton will prevent such a competitive $\mathrm{C}$-terminal backbone rearrangement. Among all well-known nondirect sequence fragment ions issued from non specific loss of neutral molecules (mainly $\mathrm{H}_{2} \mathrm{O}$ and $\mathrm{NH}_{3}$ ) and multiple backbone amide ruptures (b-type internal ions), the described $\mathrm{C}$ terminal residue exclusion is highly identifiable giving raise to a single fragment ion in the high mass range of the MS/MS spectra. The mass difference between this signal and the protonated molecular ion corresponds to the mass of the C-terminal residue. It allowed a straightforward identification of the amino acid positioned at this extremity. It must be emphasized that a neutral residue loss can be misattributed to the formation of a $y_{m-1}$ ion, i.e., to the loss of the $\mathrm{N}$-terminal residue following the $\mathrm{a}_{1}$ $\mathrm{y}_{\mathrm{m}-1}$ fragmentation channel. Extreme caution must be adopted when reading the direct sequence ion on the positive ion MS/MS spectra of singly charged peptides not to mix up the attribution of the $\mathrm{N}$ - and $\mathrm{C}$-terminal amino acids. Although such peculiar fragmentation behavior is of obvious interest for de novo peptide sequencing, it can also be exploited in proteomics, especially for studies involving digestion protocols carried out with proteolytic enzymes other than trypsin (Lys-N, Glu-C, and Asp-N) that produce arginine-containing peptides.
\end{abstract}

Electronic supplementary material The online version of this article (doi:10.1007/s13361-011-0254-1) contains supplementary material, which is available to authorized users.

Correspondence to: Christine Enjalbal; e-mail: enjalbal@univ-montp2.fr 
Key words: MS/MS, Peptide fragmentation, CID, LID, Residue exclusion, Neutral loss, C-terminal residue

\section{Introduction}

$\mathrm{T}^{\mathrm{h}}$ he accuracy of MS/MS-based peptide sequencing significantly depends on the refined knowledge of gasphase peptide chemistry to implement reliable fragmentation rules in bioinformatics tools used by the proteomics community for protein identification [1]. Many researchers have tackled worldwide such an important issue during the last decade providing a buoyant literature on peptide fragmentation chemistry upon low energy collision induced dissociation (CID) conditions and on the gas-phase structures of the major fragment ions, i.e. $\mathrm{b}$, a, and y signals. The mobile proton model [2-5] covers the mobility/sequestering of ionizing protons, which triggers the peptide chain dissociations. These $\mathrm{b}$, a, and $\mathrm{y}$ fragment ions that are directly related to the primary polyamide skeleton are used to deduce the amino acid sequence. However, many MS/MS spectra remains unassigned by sequencing algorithms due to the formation of abundant peaks that do not belong to the direct sequence ion series and related structures (internal and immonium ions, loss of $\mathrm{H}_{2} \mathrm{O}, \mathrm{NH}_{3}$ ). Many complex rearrangements have been evidenced to explain such nondirect sequence ion production [6-12], the scrambling effect being recently one of the most studied phenomena [13-22]. Indeed, these atypical peptide fragmentations deserve great attention in the search for more comprehensive dissociation pathways suitable for efficient automated MS/MS spectra interpretation. Thus, our attention was focussed on low molecular weight singly charged peptides that often failed to be identified by sequencing algorithms looking for specific rearrangement behaviors other than sequence scrambling. Following a statistical approach, we have in hand a database of MS/MS spectra recorded upon collision-induced dissociation (CID) and laser-induced dissociation (LID) conditions in ESI and MALDI mass spectrometry from 392 synthetic peptides of various amino acid composition and length [2325]. Surprisingly, the loss of the C-terminal amino acid residue that has been previously reported for some argininecontaining peptide singly charged ions [6-10] was very often observed for any of the 20 proteinogenic amino acids, whatever the MS/MS activation method. Besides, the fair to very abundant intensities of many of these fragment ions prompted us to scrutinize our available MS/MS data to define all conditions required for such a $\mathrm{C}$-terminal specific rearrangement.

The peptide database can be divided in two subsets according to the nature of the $\mathrm{C}$-terminal backbone function: a carboxylic acid (peptide free acids) or an amide (peptide amides), the latter case corresponding to digestion of amidated proteins issued from a specific C-terminal posttranslational modification that was of interest in the laboratory as part of ongoing research projects [26]. As depicted in Figure 1, among the peptide free acids, some were designed to mimic protein digest sequences such as tryptic chains having either arginine $(\mathrm{R})$ or lysine $(\mathrm{K})$ at their C-terminus [27], as well as Lys-N proteolytic peptides that all possess $\mathrm{N}$-terminal lysine $[28,29]$. Peptides illustrating trypsin miscleavages with either $\mathrm{R}$ or $\mathrm{K}$ within the sequence were also exemplified. Two situations could be encountered. First, the tryptic miscleaved peptide originated from the protein internal sequence and had either $\mathrm{R}$ or $\mathrm{K}$ at the $\mathrm{C}$ terminus. The second came from the protein $\mathrm{C}$-terminal sequence and it possessed any of the 20 proteinogenic amino acids at the C-terminal end. These two types of peptides were respectively named in Figure 1 trypsin miscleavages and C-ter trypsin miscleavages. Furthermore, the peptide collection contained some sequences that were not related to any protein enzymatic digestion. These peptides could be assigned to the C-terminal part of any protein subjected to proteolysis. Finally, we ensured that the synthetic peptide free acids were presenting an overall amino acid occurrence similar to the residue natural relative abundance in proteins as shown in Figure 1. Moreover, the 20 proteinogenic amino acids being located randomly at any position within the available sequences, we checked that the five different classes (aliphatic, aromatic, basic, acid, and not charged side chains) were inserted at least once at the C-terminal position. All sequences are reported in Table $\mathrm{S} 1$ of the Supplemental Information section.

Surprisingly, we have observed that some of these 392 peptides exhibited a peculiar MS/MS behavior leading to the abundant loss of the residue located at the $\mathrm{C}$-terminus, as

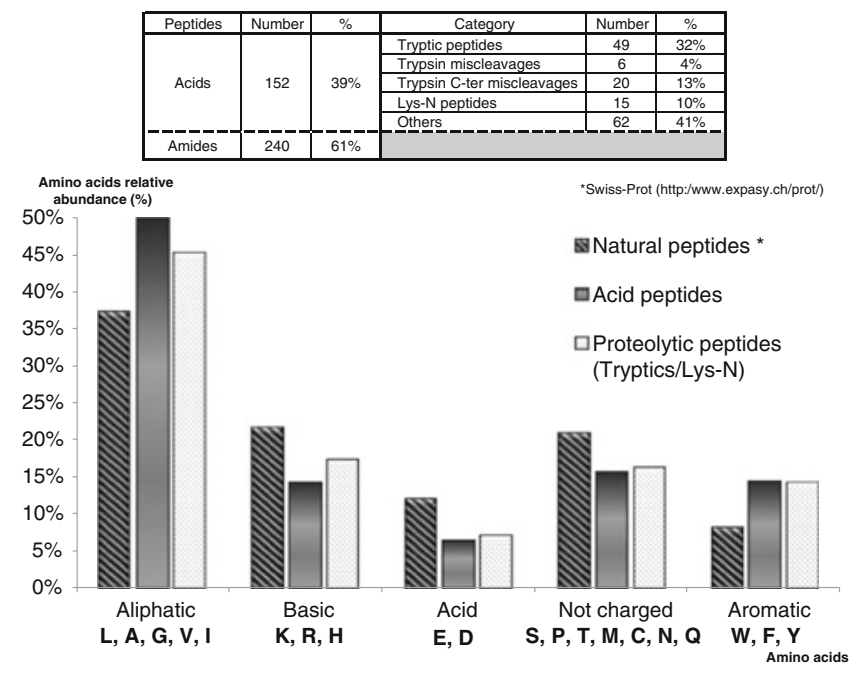

Figure 1. Database of synthetic peptides and the corresponding amino acid occurrence 
shown in Table 1. This neutral loss that has been reported from metastable decomposition [6] and from CID experiments [7-10] of singly charged arginine-containing peptide ions was observed whatever the instrument used to record the MS/MS spectra (ESI-QqTof and MALDI-TOF/TOF), and whatever the nature of the amino acid present in that position. However, it appeared that such residue exclusion only occurred when three conditions were simultaneously satisfied: (1) the precursor ion must be singly charged; (2) a basic residue must be present in the sequence; (3) the Cterminal backbone function must be a carboxylic acid. Within the frame of the mobile proton model [2-5], provided that at least one of the ionizing protons is sufficiently mobile to be intramolecularly transferred onto

Table 1. Synthetic Peptides Exhibiting C-terminal Residue Exclusion

\begin{tabular}{|c|c|c|c|c|c|c|}
\hline \multirow[t]{2}{*}{ Entry } & \multirow[t]{2}{*}{ Category } & \multirow[t]{2}{*}{ Free acid peptide sequence } & \multirow[t]{2}{*}{ Residue excluded } & \multirow[t]{2}{*}{$\mathrm{M}(\mathrm{g} / \mathrm{mol})$} & \multicolumn{2}{|c|}{ Abundance of the truncated peptide ion } \\
\hline & & & & & ESI-QqTof & MALDI-Tof/Tof \\
\hline \multicolumn{7}{|c|}{ R-containing sequences } \\
\hline R-1 & $x$ & F P A R V G S & $\mathbf{S}$ & 732,39 & + & ++++ \\
\hline $\mathrm{R}-2$ & $\times$ & F P A R V G C & $\mathbf{C}$ & 748,37 & + & ++++ \\
\hline R-3 & $x$ & F P A R V G I & $\mathbf{I}$ & 758,41 & ++ & ++++ \\
\hline $\mathrm{R}-4$ & $\bullet$ & F P A R V G K & $\mathbf{K}$ & 773,42 & +++ & ++++ \\
\hline R-5 & $\times$ & F P A R V G Q & $\mathbf{Q}$ & 773,42 & ++ & ++++ \\
\hline $\mathrm{R}-6$ & $\times$ & F P A R V G E & $\mathbf{E}$ & 774,40 & ++ & ++++ \\
\hline $\mathrm{R}-7$ & $\times$ & F P A R V G H & $\mathbf{H}$ & 782,42 & ++++ & ++++ \\
\hline $\mathrm{R}-8$ & $\bullet$ & F P A R V G R & $\mathbf{R}$ & 801,46 & ++++ & ++++ \\
\hline R-9 & $\times$ & F P A R V G Y & $\mathbf{Y}$ & 808,42 & ++ & ++++ \\
\hline $\mathrm{R}-10$ & $\times$ & L A V R I A W & $\mathbf{W}$ & 827,48 & + & + \\
\hline $\mathrm{R}-11$ & $\times$ & L R A V A I A & $\mathbf{A}$ & 712,44 & ++ & ++++ \\
\hline $\mathrm{R}-12$ & $\times$ & A V A I R D A & $\mathbf{A}$ & 714,37 & +++ & +++ \\
\hline R-13 & $x$ & W R A G F A L & $\mathbf{L}$ & 819,42 & + & +++ \\
\hline $\mathrm{R}-15$ & $\times$ & A L G S R S A Y P & $\mathbf{P}$ & 977,45 & +++ & ++++ \\
\hline $\mathrm{R}-16$ & $\times$ & M L G F R S V G Y A & $\mathbf{A}$ & 1099,50 & ++ & ++++ \\
\hline $\mathrm{R}-17$ & $\times$ & C L V A I S A R Y W & $\mathbf{W}$ & 1180,56 & + & ++ \\
\hline R-18 & $x$ & W F A P P R V G Y L & $\mathbf{L}$ & 1204,59 & ++ & ++++ \\
\hline R-19 & $\times$ & F P A R V G & $\mathbf{G}$ & 645,36 & + & + \\
\hline \multicolumn{7}{|c|}{ H-containing sequences } \\
\hline $\mathrm{H}-1$ & & F P A D H F A & $\mathbf{A}$ & 803,36 & + & + \\
\hline $\mathrm{H}-2$ & $\star$ & L G H A P E V R & $\mathbf{R}$ & 877,48 & + & + \\
\hline $\mathrm{H}-3$ & $\star$ & G E V A V L G H M K & $\mathbf{K}$ & 1039,50 & + & + \\
\hline $\mathrm{H}-4$ & $\star$ & P G A H I W A G A K & $\mathbf{K}$ & 1135,50 & + & + \\
\hline $\mathrm{H}-5$ & $\star$ & G N G Q I V F H A A R & $\mathbf{R}$ & 1168,60 & ++ & ++ \\
\hline H-6 & $\star$ & G H L P T V S E N A R & $\mathbf{R}$ & 1179,60 & + & + \\
\hline \multicolumn{7}{|c|}{ K-containing sequences } \\
\hline K-1 & $\diamond$ & K G F C L & $\mathbf{L}$ & 566,71 & + & + \\
\hline $\mathrm{K}-2$ & $\times$ & F P A K V G I & $\mathbf{I}$ & 730,43 & + & + \\
\hline $\mathrm{K}-3$ & $\diamond$ & K A D F P Q L M V & $\mathbf{V}$ & 1048,26 & + & + \\
\hline $\mathrm{K}-4$ & $\bullet$ & K E D F P Q L M V & $\mathbf{V}$ & 1106,29 & + & + \\
\hline \multicolumn{7}{|c|}{ Multipled basic residues-containing sequences } \\
\hline B-1 & $\diamond$ & K A F L H G & G & 671,79 & nd & + \\
\hline B-2 & $\bullet$ & K A F L R G & $\mathbf{G}$ & 690,83 & ++ & ++ \\
\hline B-3 & $\bullet$ & $\mathbf{K}$ A F R L G & $\mathbf{G}$ & 690,83 & + & + \\
\hline B-4 & $\star$ & A V G K K K K & $\mathbf{K}$ & 757,48 & + & + \\
\hline B-5 & $\bullet$ & K Y I W L S R A V & $\mathbf{V}$ & 1135,36 & ++ & ++++ \\
\hline B-6 & $\bullet$ & K S W D T L C M A G R F & $\mathbf{F}$ & 1414,65 & +++ & +++ \\
\hline B-7 & $\bullet$ & L H F V K M G R A W A I G R & $\mathbf{R}$ & 1639,85 & ++++ & ++++ \\
\hline B-8 & $\bullet$ & K A T C G R V N S A M Y D A I & $\mathbf{I}$ & 1686,90 & + & +++ \\
\hline B-9 & $\bullet$ & K T R Y N G M G E Q W D P D & $\mathbf{D}$ & 1696,79 & + & + \\
\hline \multicolumn{7}{|c|}{ K-terminated sequences } \\
\hline $\mathrm{X}-1$ & $\star$ & P I C A K & $\mathbf{K}$ & 530,29 & + & + \\
\hline$X-2$ & $\star$ & A G V D G P K & $\mathbf{K}$ & 642,31 & + & + \\
\hline$X-3$ & $\star$ & T P S S V L K & $\mathbf{K}$ & 730,42 & + & + \\
\hline$X-4$ & $\star$ & M W A E N K & $\mathbf{K}$ & 777,35 & + & + \\
\hline
\end{tabular}

Category

$\star$ Tryptic peptides

- Lys-N peptides

- Trypsin miscleavage peptides

$\times$ C-terminal miscleavage peptides

Abundance

$+0-25 \%$

$++26-50 \%$

$+++51-75 \%$

++++ 76-100\% 
any amide bond along the peptide backbone, multiple peptide bond ruptures will be triggered in MS/MS experiments upon precursor ion activation. These competitive fragmentation pathways led to series of ions related to the $\mathrm{N}$ terminal part of the peptide (b/a ions) and C-terminal end (y ions) allowing efficient sequencing. On the contrary, it is well known that peptides containing strong basic residues (such as arginine and histidine) sequester the ionizing proton $[30,31]$ and, thus, may be very difficult to dissociate by low energy CID activation of the monoprotonated precursor ion [32-35]. Since this situation was encountered for all peptides exhibiting the C-terminal residue exclusion (conditions 1 and 2), it confirmed that the fragmentation mechanism by rearrangement [7-10], in competition with the regular $b_{n}-y_{m}$ pathway [4], was necessarily requiring proton sequestering on a basic side chain and mobilization of the C-terminal carboxylic acid proton. Even if this C-terminal rearrangement mechanism has been debated in the literature for some times [7-10], recent investigations by Bythell et al. on the RGD tripeptide by means of experimental and theoretical work have proven that salt-bridge stabilized and anhydride transition structures were involved [10]. Thus, the structural constraints that have been established from many experimental data provide further compelling evidence of the Cterminal rearrangement mechanism established for the RGD tripeptide [10]. These results were also in agreement with literature data describing the production of truncated peptides from sodiated ions [36-38]. Lebrilla et al. have demonstrated that lithiated glycylglycine was rearranged to form an anhydride intermediate that further fragment to give the product with a carboxyl group at the new C-terminus [39]. Although neutral fragments released from both $\mathrm{N}$ - and C-termini of singly protonated peptides were studied more than a decade ago [40], the loss of a residue was identified as an aziridinone (three-membered cyclic amide) and solely related to the N-terminal part of the peptide, which accompanies $\mathrm{y}_{\mathrm{m}}$ ion formation. Working with synthetic peptides having well-defined sequences allowed to ascertain that the residue loss was produced in our case from the Cterminal end. This point was crucial for relevant peptide sequencing since a mistake in the identification of the amino acid present at one chain extremity might bring confusion between the sequence and retrosequence attribution. Indeed, a fragment obtained by $\mathrm{C}$-terminal residue elimination still contains the $\mathrm{N}$-terminal part of the original peptide but will be assigned as a y ion and thus be attributed to the Cterminal sequence as depicted in Scheme 1. Such confusion could be made since the $a_{1}-y_{m-1}$ fragmentation channel allowing the potent formation of N-terminal $\mathrm{a}_{1}$ ion and $\mathrm{C}$ terminal $\mathrm{y}_{\mathrm{m}-1}$ ion has been proposed to occur in competition with the common major $b_{n}-y_{m}$ dissociation pathway [4]. Thereafter, the designation of the fragment ion produced by C-terminal residue loss could be ambiguous. Since the remaining peptide skeleton present in this fragment ion corresponds to the $\mathrm{N}$-terminal portion, it has been described as a so-called $\left(\mathrm{b}_{\mathrm{n}-1}+\mathrm{H}_{2} \mathrm{O}\right)$ ion [7-10] and named as such in this paper.

To confirm the occurrence of such competitive ambiguous rearrangement in peptide sequencing by singly charged precursor ion activation, we report the behavior in MS/MS experiments of several peptides of various lengths containing at least one basic residue. Since some amino acids are well-known to exhibit specific reactivity in MS/MS experiments such as proline [41-44] and few residues that present functionalized side chains that can be involved in acid/base and nucleophile/electrophile reactions [32, 34, 35, 45-47], we ensured a nonbiased peptide collection with sequences possessing such tricky amino acids (see Table S1). To further assess the generality of such an exclusion fragmentation behavior, a series of peptides displaying the same sequence (FPARVGX) but differing by the nature of the Cterminal amino acid ( $\underline{X}$ classified according to their aliphatic, aromatic, not charged, acidic, and basic side chains in Figure 1) was analyzed as shown in Table 1 (entries R-1 to R-9). As a proof of concept, to ascertain the published fragmentation mechanism from protonated and cationized species [10, 38], comparative dissociation of singly charged molecular ions $\left(\mathrm{MH}^{+}\right)$of C-terminal peptide free acids and amides in ESI-QqTOF and MALDI-TOF/TOF experiments were undertaken. Besides, some sodiated ions were also dissociated and the recorded MS/MS spectra were compared with the protonated ones. Finally, the fragmenta-

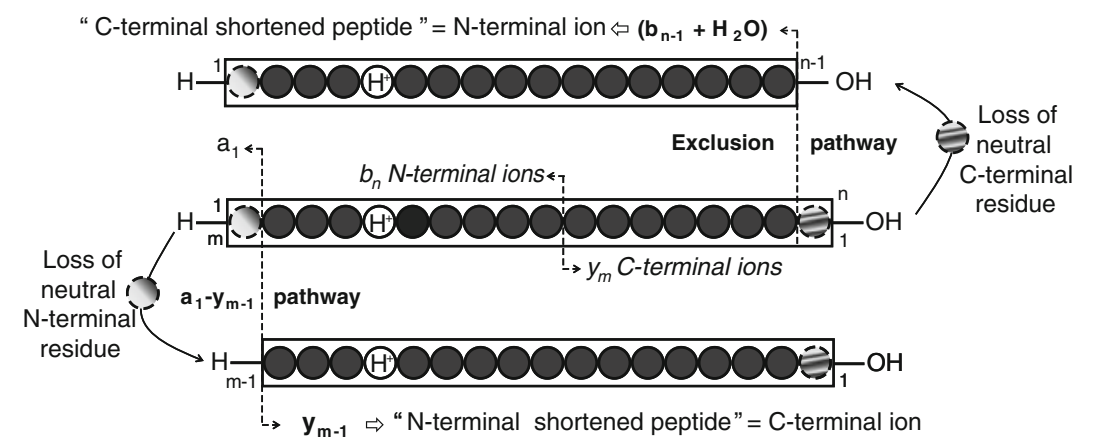

(1) Protonated basic residue $(R, H, K)$

Scheme 1. Ambiguous loss of neutral residue from $\mathrm{N}$ - and C-terminal peptide extremities 
tion profile of the gas-phase recovered truncated peptide (through an $\mathrm{MS}^{3}$ experiment) and the corresponding synthetic sequence of such considered shortened peptide $\left(\mathrm{MS}^{2}\right.$ spectrum) were compared. From all these data, we found that the relative abundance of the fragment ion resulting from the $\mathrm{C}$-terminal residue exclusion depended from both the amino acid nature and the MS/MS activation method (low energy collisionally activation in ESI-QqTof versus high energy collisionally activation/metastable decomposition in MALDI-TOF/TOF).

\section{Experimental}

\section{Chemicals and Reagents}

All solvents were of analytical grade. Acetonitrile was purchased from Carlo Erba. The deionized water used in all the experiments was obtained using a Milli-Q system (Millipore, Milford, MA, USA). MALDI matrix [2,5-dihydroxybenzoic acid (DHB) and $\alpha$-cyano-4-hydroxycinnamic acid (HCCA)] were purchased from Fluka. A peptide calibration standard kit was purchased from Bruker Daltonics.

\section{Syntheses}

Peptides were synthesized on the IBMM peptide synthesis platform using the conventional methodology of solid-phase peptide synthesis using Fmoc chemistry [48] and purified by preparative LC/MS (Autopurification System; Waters, Milford, CA, USA). According to the chosen linker, the peptides were prepared as C-terminal carboxylic acids or amides. More details are available in the Supplemental Information section.

\section{Mass Spectrometry}

Mass spectrometry analyses were conducted on instruments located in the Laboratoire de Mesures Physiques of University Montpellier 2, IBMM platform of instrumentation.

ESI mass spectra were recorded on a Q-TOF I mass spectrometer (Waters, Milford, CA, USA) fitted with an electrospray ion source. Data were acquired and processed with the MassLynx software. The mass spectrometer was calibrated in the positive ion mode using $1 \%$ phosphoric acid in water/acetonitrile solution $\left(\mathrm{H}_{2} \mathrm{O} / \mathrm{CH}_{3} \mathrm{CN}, 50 / 50\right.$, vol/ vol). Data were acquired by the TOF analyzer at 1 acquisition/s from $\mathrm{m} / \mathrm{z} 50$ to $\mathrm{m} / \mathrm{z} 2000$ with a resolution of 5000. One hundred acquisitions were summed to produce the final spectrum. Samples were dissolved in a mixture $\mathrm{H}_{2} \mathrm{O} / \mathrm{CH}_{3} \mathrm{CN}(50 / 50$, vol/vol) and infused into the ESI source at a flow rate of $5 \mu \mathrm{L} / \mathrm{min}$. Voltages were set at $+2.5 \mathrm{kV}$ for the capillary and adjusted for the sampling cone. The source was heated at $80{ }^{\circ} \mathrm{C}$. Nitrogen constituted both nebulizing and desolvation gas. The latter was heated at $150{ }^{\circ} \mathrm{C}$. In MS/MS experiments, the second quadrupole analyzer was set in the rf mode using argon as collision gas and the collision energy varied from 25 to $90 \mathrm{eV}$ depending on the samples to get optimal fragmentation.

MALDI mass spectra were recorded on an Ultraflex III TOF/TOF instrument (Bruker Daltonics, Wissembourg, France) equipped with LIFT capability. A pulsed Nd:YAG laser at a wave length of $355 \mathrm{~nm}$ was operated at a frequency of $100 \mathrm{~Hz}$ (MS data) or $200 \mathrm{~Hz}$ (MS/MS data) with a delayed extraction time of $30 \mathrm{~ns}$. The source was operated in the positive mode. Data were acquired with the Flex Control software and processed with the Flex Analysis software. A solution of either the $\alpha$-cyano-4-hydroxycinnamic acid (HCCA) matrix in water/acetonitrile $(70 / 30, \mathrm{vol} / \mathrm{vol})$ at a concentration of $10 \mathrm{mg} / \mathrm{mL}$ or the 2,5-dihydroxybenzoic acid (DHB) matrix in water/acetonitrile $(50 / 50, \mathrm{vol} / \mathrm{vol})$ at a concentration of $10 \mathrm{mg} / \mathrm{mL}$ was mixed with the peptide sample in equal amount and $0.5 \mu \mathrm{L}$ of this solution was deposited onto the MALDI target according to the dried droplet procedure. After evaporation of the solvent, the MALDI target was introduced into the mass spectrometer ion source. External calibration was performed with the commercial peptide mixture (calibration peptide standard 2, Bruker Daltonics, Wissembourg, France). MS data were acquired under the following MS conditions. An acceleration voltage of $25.0 \mathrm{kV}$ (IS1) was applied for a final acceleration of $21.95 \mathrm{kV}$ (IS2). The reflectron mode was used for the TOF analyzer (voltages of 26.3 and $13.8 \mathrm{kV}$ ). Mass spectra were acquired from 250 laser shots, the laser fluence being adjusted for each studied sample (laser fluence 1). Ions were detected over a mass range from $\mathrm{m} / \mathrm{z} 200$ to 2000. MS/MS data were acquired under the following conditions. An acceleration voltage of $8.0 \mathrm{kV}$ (IS1) was applied for a final acceleration of $7.25 \mathrm{kV}$ (IS2). The reflectron mode was used for the TOF analyzer (voltages of 29.5 and $13.9 \mathrm{kV}$ ). Mass spectra were acquired from 600 to 800 laser shots, the laser fluence being adjusted for each studied peptide above the threshold for generation of molecular ions (laser fluence $2>$ laser fluence 1). MS/MS experiments were performed under laser induced dissociation (LID) conditions with the LIFT cell voltage parameters set at $19.0 \mathrm{kV}$ (LIFT 1) and $3.2 \mathrm{kV}$ (LIFT 2) for a final acceleration of $29.5 \mathrm{kV}$ (reflector voltage) and a pressure in the LIFT cell around $4 \times 10^{-7}$ mbar. The precursor ion selector was set manually to the first monoisotopic peak of the molecular ion pattern for all analyses. For LID experiments, no collision gas was added (gas off spectra). For LID/ CID experiments (gas on spectra), the same tuning was used but argon was allowed to fill the collision cell (pressure around $2 \times 10^{-7} \mathrm{mbar}$ ).

\section{Results and Discussion}

Among all available peptide free acids dissociated upon CID on a QqTOF mass analyzer configuration (Table S1 of the Supplemental Information section), for roughly $25 \%$ of the available MS/MS synthetic peptide data we observed an abundant fragment ion that corresponded seemingly to a 
truncated sequence where the residue in the C-terminal position has been lost. As expected from published data on small arginine-containing peptides [7-10], this dissociation only occurred from the protonated precursor ion leading to a single atypical fragment ion in the upper mass range of the MS/MS spectrum. The loss of a neutral residue was only observed for peptides in the MS/MS data set corresponding to the free acids. Moreover, in that category, only peptides bearing a basic amino acid in their sequence such as arginine, histidine and lysine revealed C-terminal exclusion provided the singly charged precursor ion was selected for activation/dissociation. These two constraints must be simultaneously satisfied to trigger the C-terminal sequence truncation.

The 42 peptide free acids (over 152 entries) exhibiting such amino acid exclusion are reported in Table 1. They are classified according to the basic residue present within the sequence, i.e., arginine (entries R-1 to R-19), histidine (entries H-1 to H-6), or lysine (entries K-1 to K-4), which are required to trigger the $\mathrm{C}$-terminal exclusion with fair to high intensities. Peptides possessing multiple basic residues were counted separately (entries B-1 to B-9). Obviously, the C-terminal position has not been considered for such a categorization, this amino acid being lost as a neutral molecule. It should be noted that few tryptic peptides that were all terminated by lysine behaved unexpectedly upon collision-induced activation of the singly charged molecular ion (roughly $10 \%$ of all tryptic peptides). Although these peptides did not contain any basic amino acid except the Cterminal one $(\mathrm{K})$, they produced the residue exclusion. This has not been observed previously, the formation of $\left(b_{n-1}+\right.$ $\mathrm{H}_{2} \mathrm{O}$ ) ion being only known up to now to be promoted by the presence of basic amino acids in a non-C-terminal position $[7,10]$. In particular, such behavior in CID has been reported for deprotonated peptides containing C-terminal glutamic acid, aspartic acid, or serine residues [9]. Nevertheless, the corresponding fragment ion issued from nonbasic residue-containing tryptic peptides was always recorded with a low abundance as depicted in Table 1. These C-terminal lysine peptides were thus considered separately (entries X-1 to X-4).

To illustrate this specific dissociation pathway, we choose the two arginine-containing peptide free acids ALGSRSAGYP and WFAPPRVGYL (Table 1, entries R-15 and R-18, respectively), giving rise to an abundant loss of $97 \mathrm{Da}$ (proline residue, P) and $113 \mathrm{Da}$ (leucine residue, L) from the $\mathrm{MH}^{+}$precursor ions (R-15: $m / z$ 978.5 $\rightarrow m / z 881.5$ and R-18: $\mathrm{m} / \mathrm{z} \quad 1205.6 \rightarrow \mathrm{m} / \mathrm{z}$ 1092.4, respectively) as displayed in Figure 2. More examples of histidine- and lysine-containing peptides are provided in the Supplemental Information section (Figures $\mathrm{S} 1$ to $\mathrm{S} 3$, entries $\mathrm{H}-5, \mathrm{~K}-4$, and $\mathrm{X}-1$ in Table 1).

In the search for previous description of such elimination of the C-terminal residue during peptide sequencing in proteomics studies, fragment ions assigned as $\left(\mathrm{b}_{\mathrm{n}}+\mathrm{H}_{2} \mathrm{O}\right)^{+}$or $\left(b_{n-1}+\mathrm{H}_{2} \mathrm{O}\right)^{+}$ions has been occasionally noted on few published MS/MS spectra of monoprotonated peptides [49, 50], but they were not considered significant for bioinformatics tools due to their very low relative abundance. Since peptide sequencing is most of the time undertaken in the positive mode by dissociation of singly and multiply charged molecular ions, we decided to further investigate this rather abundant ion formation to identify the experimental conditions prerequisite for such amino acid neutral loss in the positive mode.

At this stage of our studies, we needed to answer several questions to refine the precise context of this C-terminal rearrangement:

- Is it dependent on the ion activation method?

- Is the free carboxylic acid function really compulsory for exclusion?

- Is the charge state of the selected precursor ion actually playing a role?

- Is it dependent on the nature of the amino acid positioned at the $\mathrm{C}$-terminus?

- Is the basic residue necessary for the exclusion behavior?

- What is the significance of the exclusion pathway compared with the production of all other non-scrambled sequence fragment ions, which are not directly issued from the $b_{n}-y_{m}$ backbone amide pathway?

\section{Influence of Precursor Ion Activation Method on C-Terminal Residue Exclusion}

To answer the first question, all 42 peptide free acids previously analyzed in ESI-QqTOF were subjected to MALDI-TOF/TOF experiments making available two sets of MS/MS spectra recorded with complementary dissociation techniques based on low- and high-energy CID fragmentations. In contrast to the former ESI-MS/MS setup, MALDI-TOF/TOF is not only limited to CID but allows also dissociation induced by laser irradiation known as laserinduced dissociation (LID) [51]. In such a case, no gas was added to the collision cell; only variation of the laser fluence in the ion source was employed to trigger the dissociation processes according to metastable fragmentation in a field free region [52]. Given the availability of both LID and LID/ CID high energy dissociation regimes, MALDI-TOF/TOF constitutes a major versatile analytical tool in proteomics $[53,54]$ and more generally in any field requiring high throughput analyses [55]. The same results were obtained under all dissociation conditions as depicted in Table 1. All C-terminal amino acid exclusions that were detected in low energy CID were also seen in LID and LID/CID MS/MS spectra. The corresponding fragment ion, i.e., the protonated shortened peptide, was as abundant in MALDI as in ESI MS/MS, as seen in Figures 2 and 3 for instance. In a high number of cases, this ion signal was even more intense in MALDI than in ESI dissociations (Table 1). To evaluate the relative abundance of the fragment ion under interest, the 

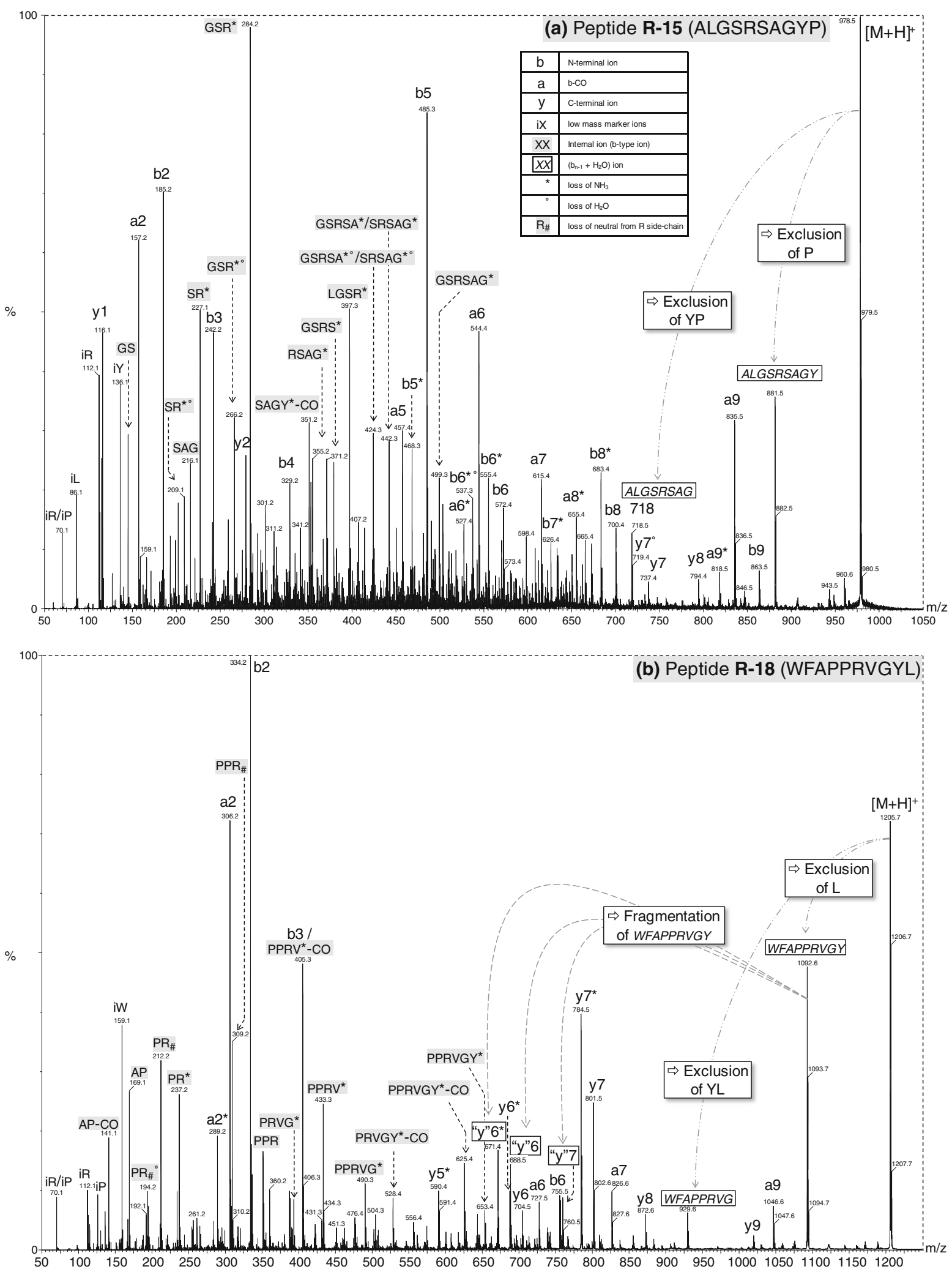

Figure 2. $\mathrm{ESI} M S / M S$ spectra upon CID of the $[\mathrm{M}+\mathrm{H}]^{+}$precursor ion of (a) peptide $\mathrm{R}-15$ (ALGSRSAGYP), (b) peptide $\mathrm{R}-18$ (WFAPPRVGYL) 
precursor ion was not considered since ESI and MALDI data were not acquired under the same MS/MS process. Hence, the signal related to the $\mathrm{C}$-terminal residue exclusion was measured according to the most intense fragment signal (base peak of the MS/MS spectrum) as described in Table 1. Changing the collision energy or the laser fluence in CID and LID MS/MS experiments did not really alter the abundance of the observed shortened peptide ion remaining weak $(+)$, fair $(++)$, abundant $(+++)$, or very abundant $(++++)$. Moreover, to enlarge the scope of such observation, other experimental parameters were also modified such as the nature of the matrix and the combination of precursor ion activation (LID and LID combined with CID). For all studied 42 peptide dissociations, the MS/MS data recorded with 2,5-dihydroxybenzoic acid matrix were very similar to the ones with $\alpha$-cyano-4-hydroxycinnamic acid. No major difference was noticed between high energy LID and LID/ CID regimes in terms of peptide fragment ion production, as already observed in previous MALDI-TOF/TOF studies $[24,25,56]$. Finally, some peptides that did not exhibit the exclusion in ESI-QqTOF were also tested in MALDI-TOF/ TOF and as expected no truncated protonated peptide was detected. The C-terminal residue exclusion was thus not dependent on the precursor ion vibrational activation method.

\section{Influence of the C-Terminal Backbone Function on C-Terminal Residue Exclusion}

None of the peptides terminated by an amide function (240 sequences, Table S1) exhibited the C-terminal neutral loss, indicating that the presence of a carboxylic acid at the Cterminus was compulsory to trigger the residue exclusion, while keeping the terminal hydroxyl group onto the produced truncated peptide ion. To reinforce this statement, some of the peptides exhibiting the C-terminal exclusion were prepared as amides, the $\mathrm{C}$-terminal carboxylic acid function being replaced by the amide function as the only modification. As expected, the latter amidated sequences did not lose their final residue. Besides, regarding these two peptide free acid and amide MS/MS data subsets, sodiated peptide free acids showed a charge-mediated rearrangement leading to the loss of the last residue whereas the sodiated peptide amides were found to behave differently, showing no such C-terminal amino acid exclusion. Such results were in good agreement with collision activated dissociation experiments that were observed in previous studies with sodiated C-terminal free acid or amide peptides [36, 39].

To ascertain these results, two analytical strategies were undertaken by performing multiple dissociation stages and by fragmenting sodiated molecular ions.

First, $\mathrm{MS}^{3}$ experiments were conducted to dissociate the shortened peptide fragment ion. For instance, the $\mathrm{MS}^{3}$ mass spectra recorded in ESI-QqTOF from the truncated Cterminal fragment of the two selected singly protonated peptide free acids (ALGSRSAGY from ALGSRSAGYP and
WFAPPRVGY from WFAPPRVGYL) are reproduced in Figure 4. These mass spectra can be compared with the MS/ MS data recorded in both CID ESI-QqTOF and LID MALDI-TOF/TOF shown in Figures 2 and 3, respectively. As expected, the truncated ions that were dissociated showed again the exclusion of the $\mathrm{C}$-terminal residue while keeping the other N-terminal related sequences ions unchanged, proving that the peptide structural modification only affected the C-terminal part and confirming the structure of such a sequence fragment ion. Moreover, to gain confidence in the attribution of a $\left(b_{n-1}+H_{2} \mathrm{O}\right)$ ion for the truncated peptide fragment ion and gain better insights into the rupture pathway, the $\mathrm{MS}^{3}$ data of two peptides (R-1: FPARVGS and R-4: FPARVGK) were matched up to the MS/MS spectrum of the corresponding synthetic truncated peptide (FPARVG) as displayed in Figure 5. The two $\mathrm{MS}^{3}$ were similar to the $\mathrm{MS}^{2}$ data of the short synthetic peptide. The fragment ion produced by $\mathrm{C}$-terminal residue exclusion was certainly structurally very close to a linear protonated sequence.

Second, sodiated molecular ions of peptide free acids $\left(\mathrm{MNa}^{+}\right)$were fragmented and the MS/MS data were compared with the ones recorded from the corresponding protonated species $\left(\mathrm{MH}^{+}\right)$. Regarding the former, the exclusion of the $\mathrm{C}$-terminal residue was observed as expected from literature data [36, 39] (Figure S4, entry K-4). Besides, most of the fragment ions that were detected from the $\mathrm{MNa}^{+}$precursor ion corresponded to the sodiated or protonated species of the sequence fragment ions recorded from the $\mathrm{MH}^{+}$species. This experiment allowed gathering additional information leading to the C-terminal sequence restriction from charge-sequestered molecular ion as proposed by Bythell et al. [10] and Lebrilla et al. [39].

\section{Influence of the Charge State of the Precursor Ion on C-Terminal Residue Exclusion}

Although it has been depicted in the literature that some peptides were prompt to lose a part of their chain as a neutral molecule both from the $\mathrm{N}$ - and $\mathrm{C}$-termini of their sequence, it was only described from doubly charged precursor ions resulting in doubly charged sequence ions $\left(\mathrm{b}_{\mathrm{n}}{ }^{2+}\right.$ and $\mathrm{y}_{\mathrm{m}}{ }^{2+}$ series) [57]. The exclusion of one residue from doubly charged molecular ion dissociation was never spotted in our peptide ESI-QqTOF MS/MS database. The lack of mobile proton was thus necessary for the rearrangement mechanism. Trapping all ionization protons was obviously more difficult to achieve from multiply charged ions of proteolytic peptides compared with singly charged species. Taking into account that most of the proteomic studies are currently carried out according to shotgun strategies involving the collision-induced dissociations in ESI-MS/MS of doublyand triply charged precursor ions [58], the described exclusion phenomenon mainly concerns sequencing methodologies based on MALDI-TOF/TOF analyses. This atypical 

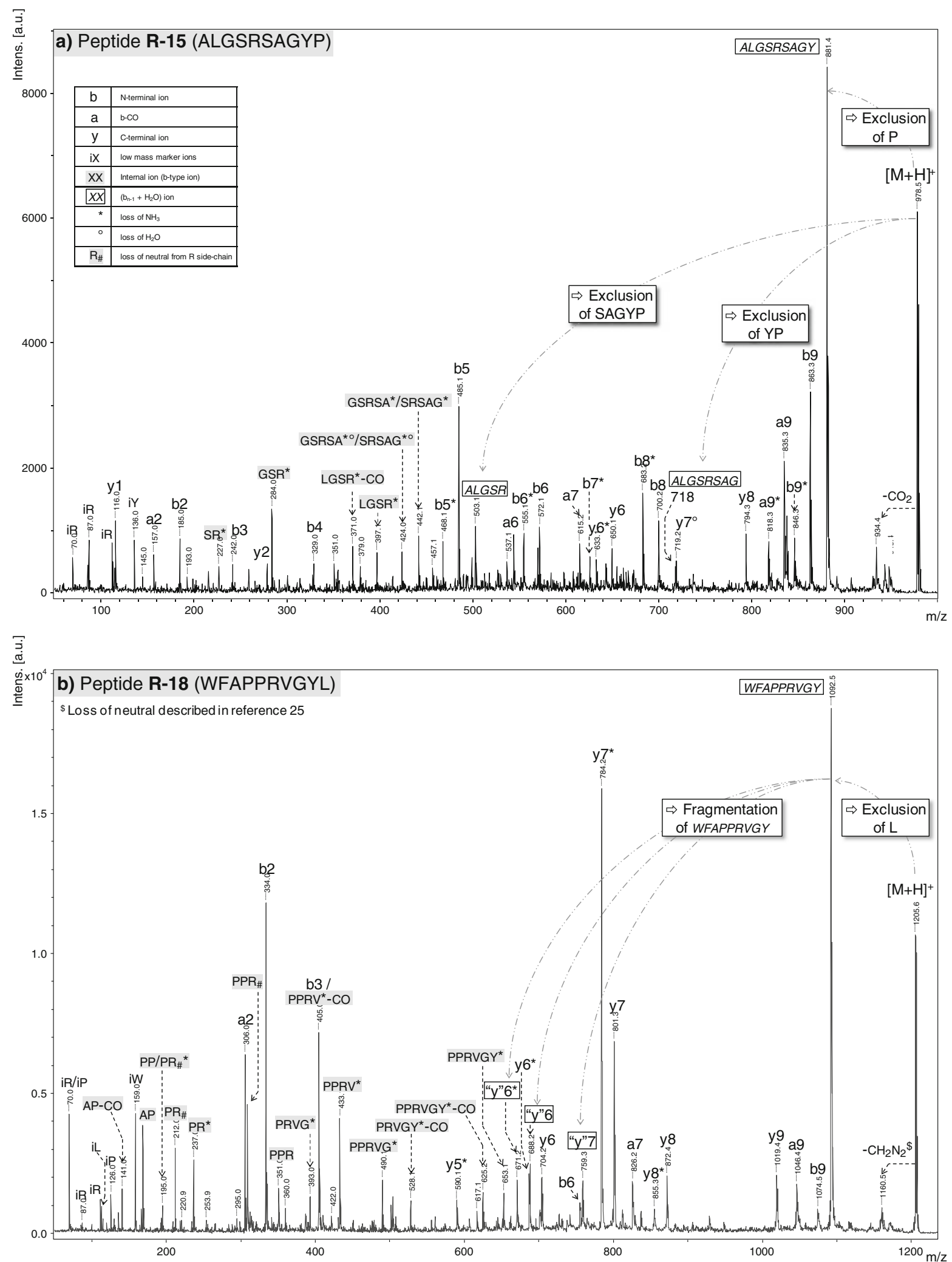

Figure 3. LID MALDI MS/MS spectra of the $[\mathrm{M}+\mathrm{H}]^{+}$precursor ion of (a) peptide R-15 (ALGSRSAGYP), (b) peptide R-18 (WFAPPRVGYL) 



Figure 4. $\mathrm{ESI} \mathrm{MS}^{3}$ spectra upon $\mathrm{CID}$ of the $[(\mathrm{M}-\mathrm{X})+\mathrm{H}]^{+}$precursor ion of (a) peptide R-15 (ALGSRSAGYP), (b) peptide R-18 (WFAPPRVGYL) 


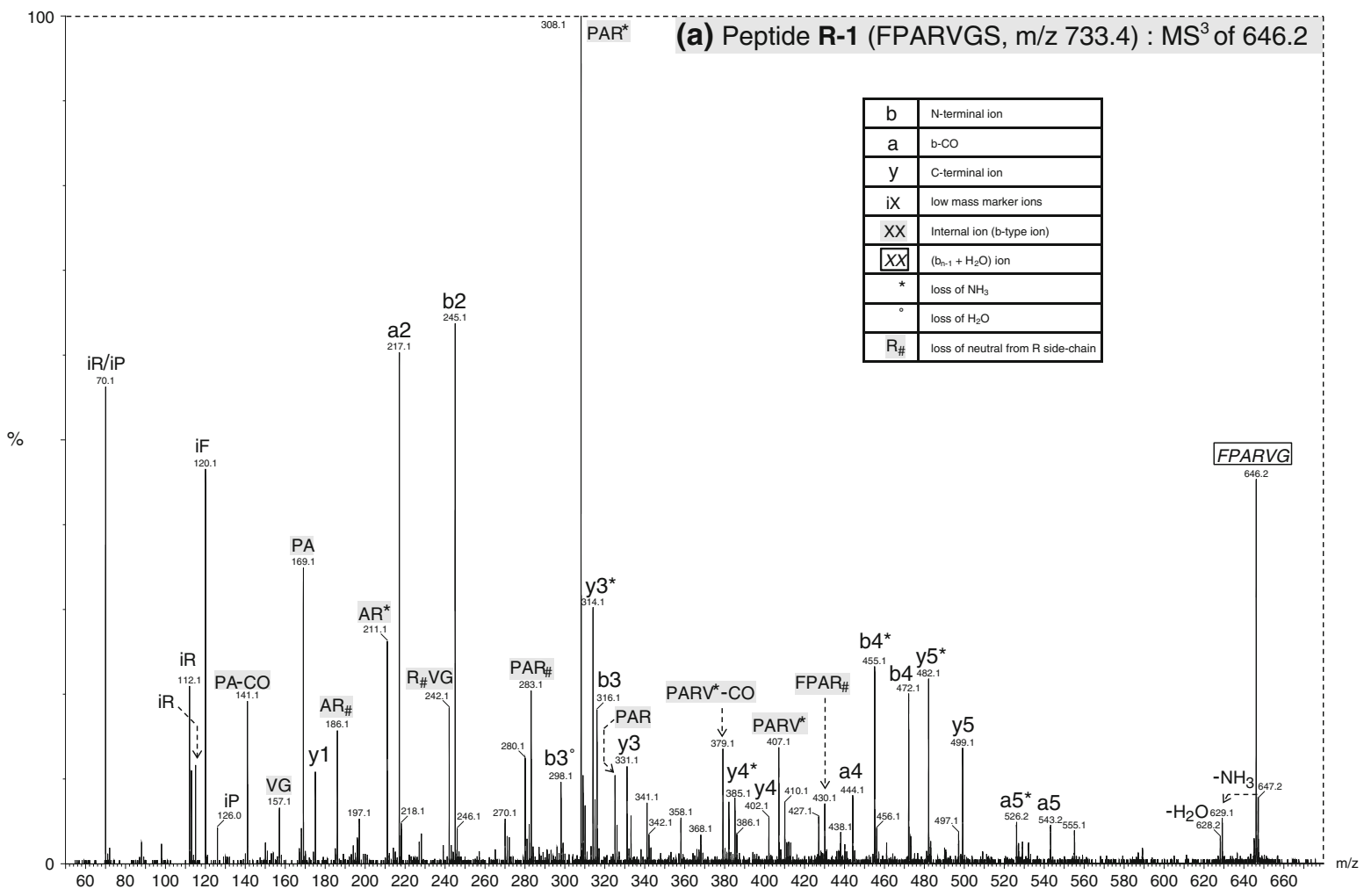

${ }^{100}$ (b) Peptide R-3 (FPARVGI, m/z 758.4) : MS $^{3}$ of 646.2

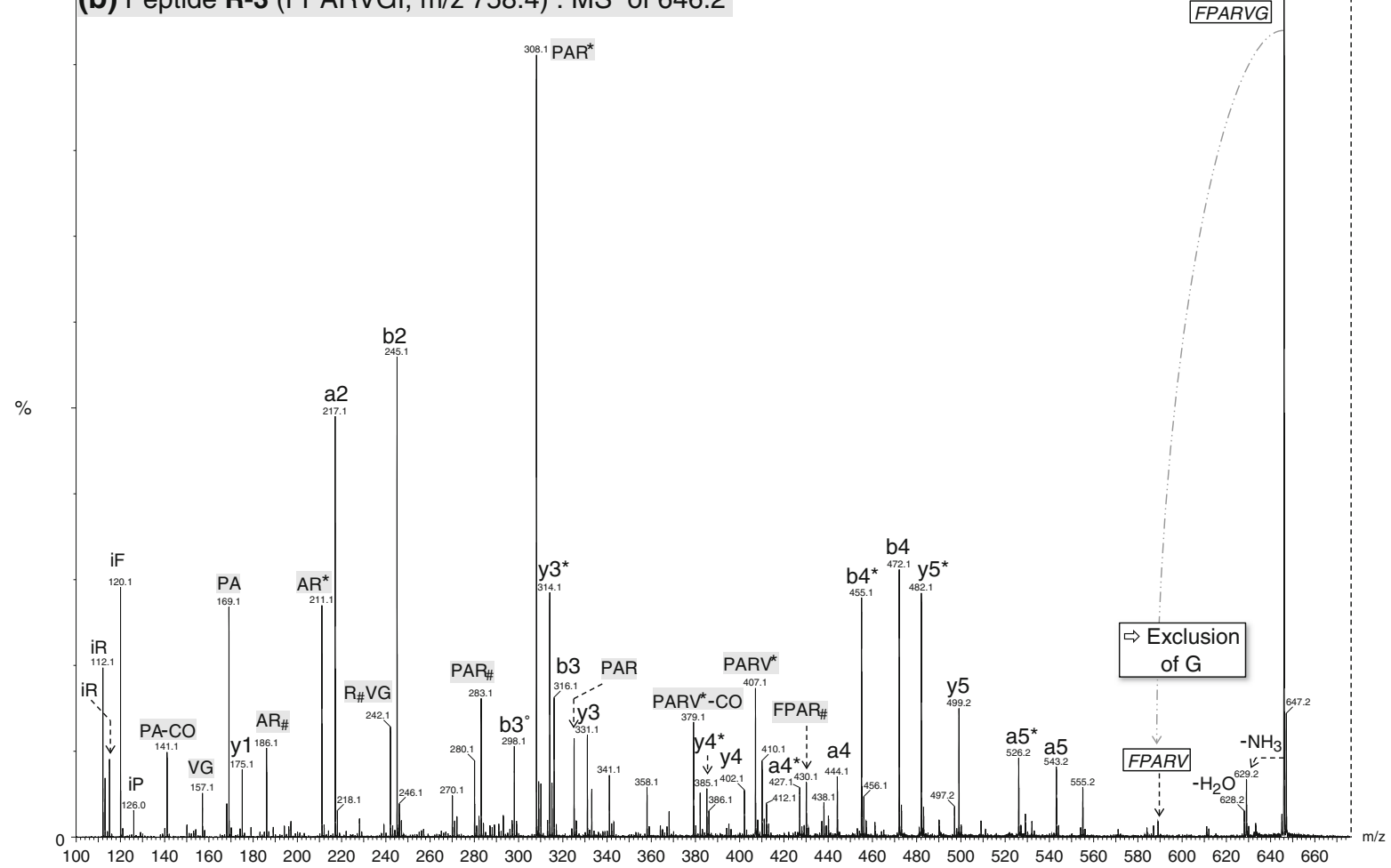

Figure 5. (Continued on next page) 


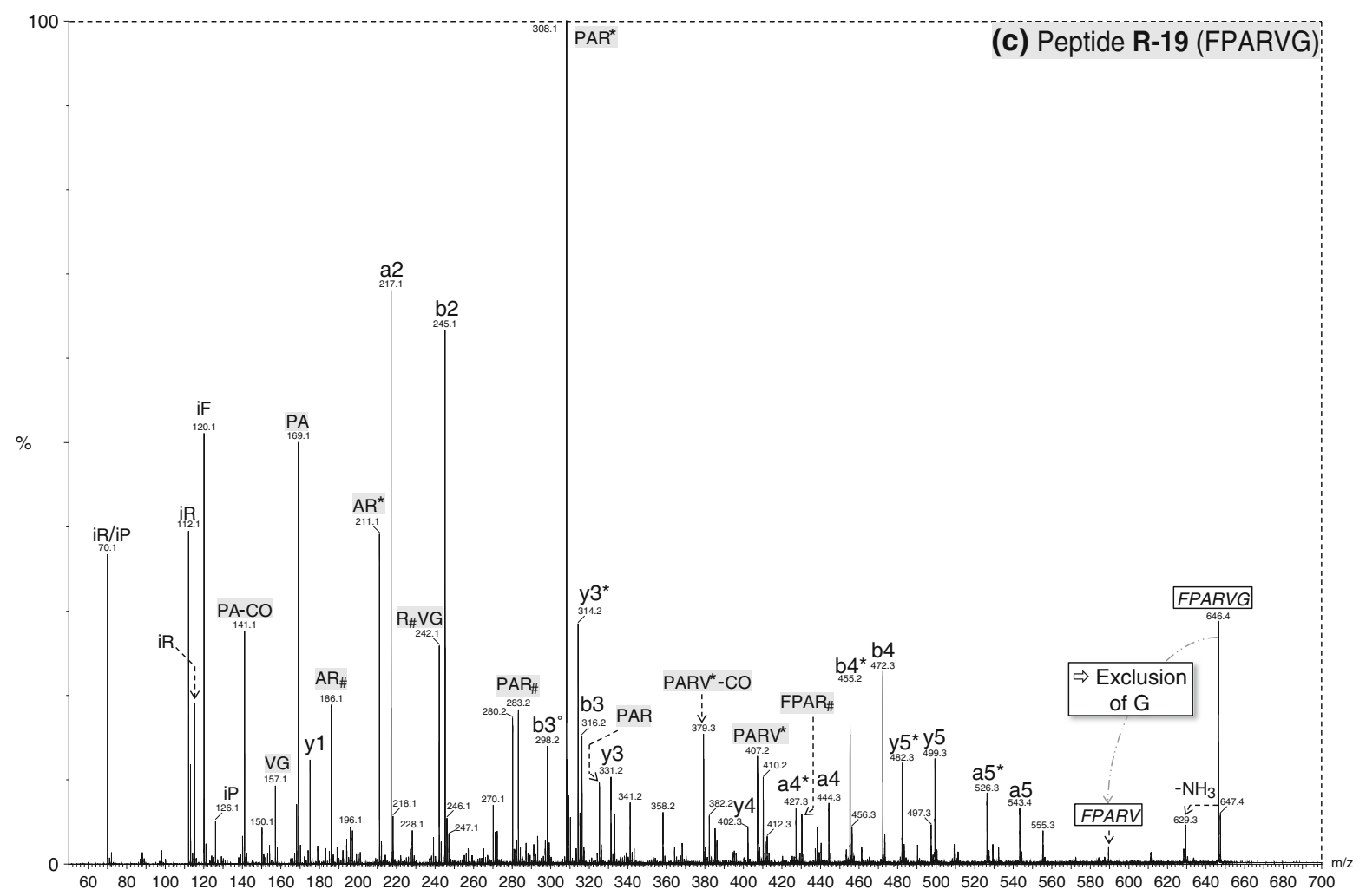

Figure 5. ESI $\mathrm{MS}^{3}$ spectra upon CID of the $[(\mathrm{M}-\mathrm{X})+\mathrm{H}]^{+}$precursor ion of (a) peptide R-1 (FPARVGS), (b) peptide R-3 (FPARVGI), and ESI MS/MS spectra upon CID of the $[\mathrm{M}+\mathrm{H}]^{+}$precursor ion of (c) peptide R-19 (FPARVG)

fragmentation might be deleterious for efficient correct sequence assignment, especially when proteolysis is carried out with others enzymes than trypsin such as Lys-N [28], Asp-N [59], and Glu-C [60] proteases, which produce peptides bearing arginine and histidine anywhere within the proteolytic sequences.

\section{Influence of the Amino Acid Positioned at the C-Terminus on C-Terminal Residue Exclusion}

A series of peptide free acids differing from the nature of the amino acid at the C-terminus (FPARVG $\underline{X}$ ) were prepared to ascertain the influence of this residue on the exclusion. At least one amino acid from each class (aliphatic, aromatic, not charged, acidic, and basic side chains) was selected for the determination of the significance of the C-terminal position $(\underline{X}=I, Y, S, C, Q, E, R$, $\mathrm{K}, \mathrm{H})$. All peptides with different molecular ion $\mathrm{m} / \mathrm{z}$ values exhibited upon activation the same fragment ion at $\mathrm{m} / \mathrm{z} 646$ issued from the amino acid exclusion and corresponding to the common protonated FPARVG sequence ion (Figure 6, entries R-1, R-4, and R-8 in Table 1). Besides, as discussed previously, the MS/MS spectrum of the synthetic FPARVG peptide was identical to any of the $\mathrm{MS}^{3}$ data recorded from the $\mathrm{m} / \mathrm{z} 646$ (exclusion ion present in all dissociation spectra). Thus, production of such a non-scrambled fragment ion was not dependent on the nature of the amino acid located at the extreme sequence end undergoing the rearrangement. However, the abundance of this ion was affected. Very surprisingly, in contrast to literature data $[7,9,10]$, the presence of a basic residue at the C-terminal position provided the most intense signal for the neutral loss, as demonstrated in Table 1, by comparing the relative abundance of the $m / z 646$ ion both in ESI- and MALDIMS/MS (Figure 6, Figures S5 and S6, entries R1 to R-9). Altogether, the exclusion occurred from all classes of amino acids (Table 1). All aliphatic, aromatic, basic, and acid residues were excluded at least once. Only the loss of methionine, threonine, and asparagine belonging to the non-charged residues was not exemplified in our peptide free acid data set, whereas serine, proline, cysteine, and glutamine were successfully tested.

\section{Necessity of the presence of at least one basic amino acid on C-terminal residue exclusion}

Provided that singly charged precursor ions of peptide free acid were activated, only sequences bearing a basic residue $(\mathrm{R}, \mathrm{H}$, or $\mathrm{K})$ showed the $\mathrm{C}$-terminal neutral exclusion. Above all, it should be emphasized that arginine caused the most outstanding exclusion as previously observed by others [6-10]. Indeed, compared with histidine and lysine, the 

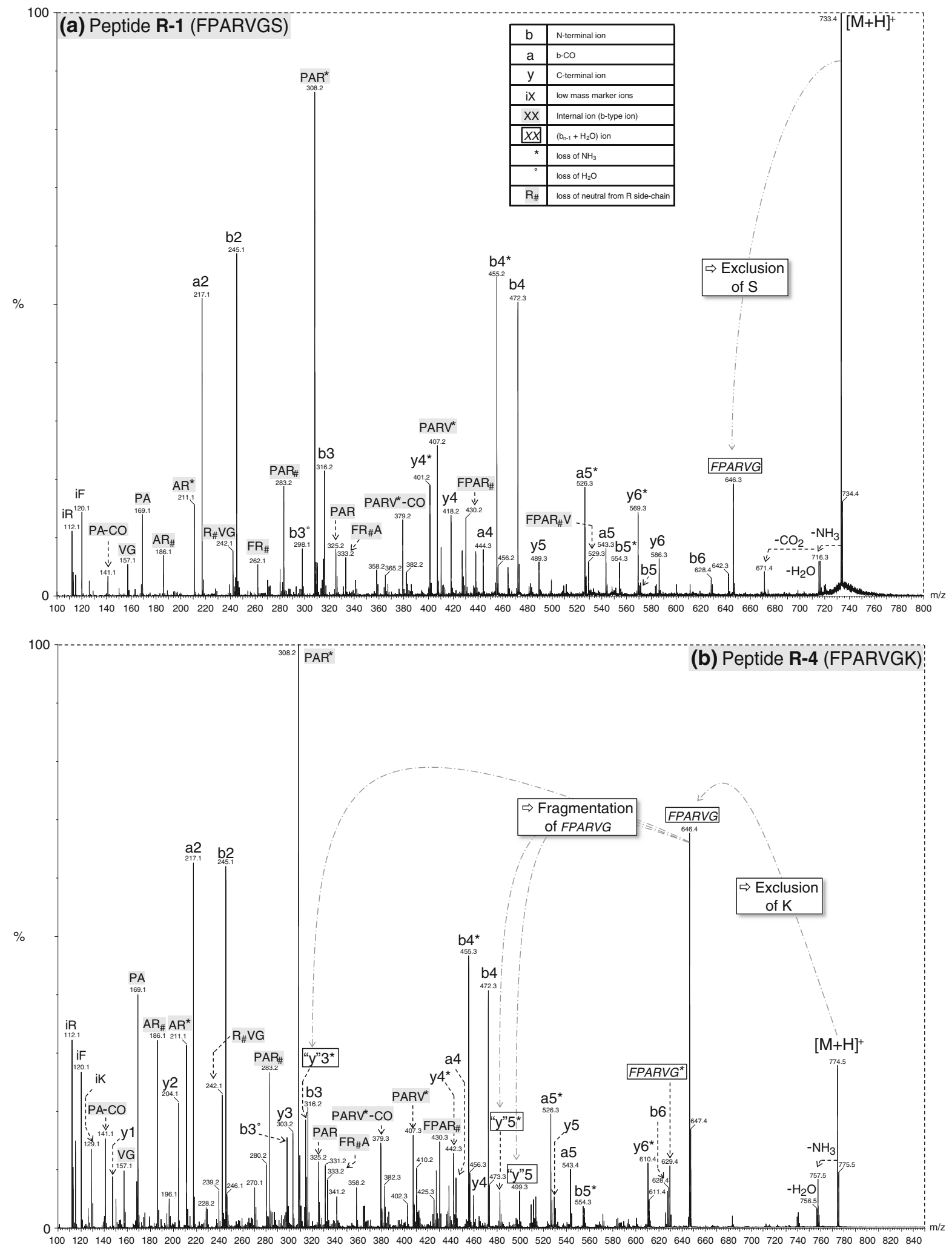

Figure 6. (Continued on next page) 


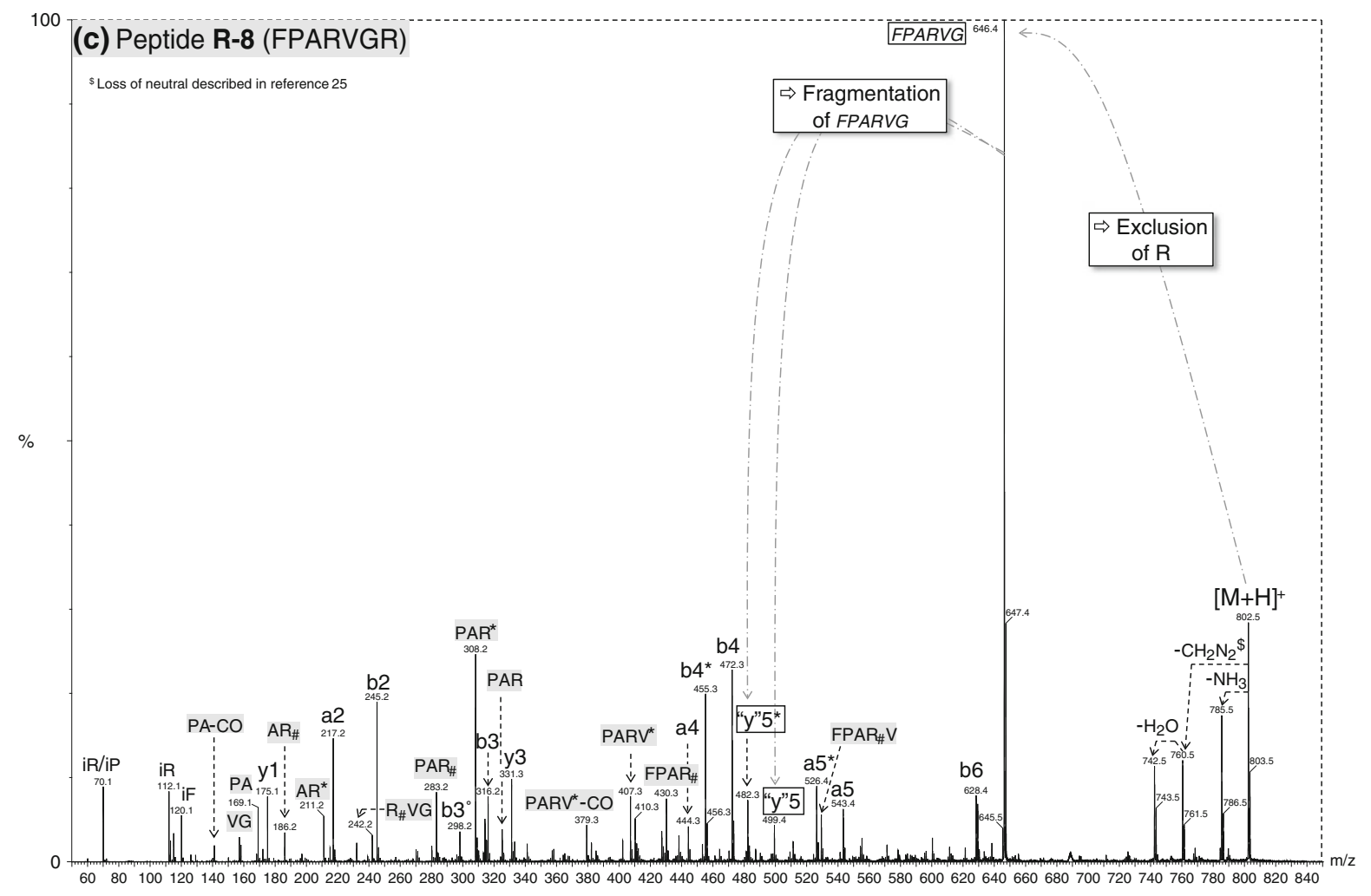

Figure 6. ESI MS/MS spectra upon CID of the $[M+H]^{+}$precursor ion of (a) peptide R-1 (FPARVGS), (b) peptide R-4 (FPARVGK), and (c) peptide R-8 (FPARVGR)

presence of arginine within the chain led to the most abundant truncated peptide, which is encountered in the case of trypsin miscleavage of the C-terminal protein sequence or with other digestion enzymes (Lys-N, Asp-N, Glu-C). This exclusion signal was even more intense, provided that another basic residue $(\mathrm{R}, \mathrm{H}$, or $\mathrm{K})$ was located at the $\mathrm{C}$-terminal position. The latter situation with $\mathrm{C}$ terminal $\mathrm{R}$ and $\mathrm{K}$ corresponds to trypsin miscleavage peptides (Table 1, entries R-4, R-8, B-7). When histidine and lysine were present within the sequence, the exclusion was less prominent even for tryptic peptides terminated by arginine (Table 1, entries $\mathrm{H}-2, \mathrm{H}-5, \mathrm{H}-6$ ) or by lysine (Table 1, entries H-3, H-4). The relative position of the basic residue sequestering the ionizing proton in the sequence did not significantly influence the C-terminal exclusion (Table 1, entries R-11, R-12). On the other hand, we have unexpectedly observed lysine exclusion for some lysine-terminated tryptic peptides that did not contain any other additional basic residue (Table 1, entries X-1 to X-4). The fragment ion was always weak and this behavior was never encountered with C-terminal arginine-terminated tryptic peptides. Considering all these results, in the context of trypsin digestion, the detection of an abundant truncated ion from the singly charged precursor ion strongly indicated a miscleavage peptide bearing arginine within the chain. Besides, the neutral loss designated the C-terminal residue (loss of 128 for $\mathrm{K}$ and loss of 156 for R). For tryptic peptides that were assigned as miscleavage sequence in conventional proteomic shotgun workflow, it could be judicious to perform the dissociation of the singly charged molecular ion, either in ESI- or MALDI-MS/MS, to ascertain the sequencing output by observing, or not, the expected neutral loss of 128 or $156 \mathrm{Da}$.

\section{Importance of the Exclusion Pathway among the Production of Non-Scrambled Sequence Fragment Ions Other than $b_{n} / a_{n} / y_{m}$ Ions}

Efficient peptide sequencing relies on the extensive formation of complementary $b_{n}$ and $y_{m}$ fragment ion series giving information on both $\mathrm{N}$-terminal and $\mathrm{C}$-terminal chains, respectively. However, in addition to such common protonated amide backbone dissociation producing direct sequence ions, i.e., protonated five-membered ring oxazolones (b ions) and protonated truncated peptides (y ions), other fragmentation pathways have been reported in the literature [46]. Indeed, after the ionizing proton migration along the peptide chain, several dissociation mechanisms are in competition, leading to the production of ions that may not be directly related to the initial primary sequence [4]. Such ions formed by rearrangement and multiple bond cleavages disturb the MS/MS spectra and may even lead to incorrect sequence assignment. One illustration of such detrimental behavior is known as peptide scrambling by means of cyclization and reopening of $b_{n}$ ions $[12,13]$. The extent of such nondirect sequence fragment ion formation and the impact of these sequence permutations on peptide 
identification relevance in shotgun proteomics studies are under debate today $[14,15]$. Despite the great interest raised by the scrambling phenomenon [12-22], less attention has been devoted in the proteomics community to the presence of fragment ions that are not produced by the conventional $b_{n}-y_{m}$ backbone amide pathway but that retain the primary sequence information. As such, one can mention, first, nonspecific fragmentation by the loss of neutral molecules (mainly $\mathrm{H}_{2} \mathrm{O}, \mathrm{NH}_{3}, \mathrm{CO}, \ldots$ ) $[61,62]$, and second, the production of internal fragment ions [63, 64], especially when residues such as proline, histidine, and arginine were present in the sequence $[23,24]$. These 'parasite' additional ions complicated the MS/MS spectra, which were overall exhibiting lots of ion series $\left(b_{n}, a_{n}, y_{m}\right.$, and so-called ' $b_{n}$ type' internal ions), but they are less deleterious for correct sequencing than scrambled sequences. Although the detection of these non-scrambled internal fragments did not hamper automatic peptide MS/MS assignment in proteomic workflow [15], we believe that they can provide relevant information for de novo peptide sequencing, especially for the C-terminal amino acid exclusion. Thus, we have explored our peptide data set to probe the formation extent of fragment ions that keep the primary sequence unaffected but differs from the fully characterized $b_{n} / a_{n}$ and $y_{m}$ ions. As expected, the loss of water and ammonia, as well as the formation of non scrambled internal b-type ions were observed for some peptides, leading to duplicated sequence ion series on the MS/MS spectra. The C-terminal exclusion behavior contrasts with all aforementioned fragmentations initiating multiple formations of ions from the activated precursor ion (such as series of $b_{n}, a_{n}, y_{m}, b_{n}-\mathrm{H}_{2} \mathrm{O}, b_{n}-\mathrm{NH}_{3}$, internal ions, ...). Only very few ions in the MS/MS spectra were related to a C-terminal neutral loss, since in most cases, only the extreme residue was concerned and scarcely the Cterminal dipeptide or tripeptide. The fragment ions corresponding to these dissociations were not as abundant as the single amino acid exclusion. For instance, the MS/MS data of the two peptide free acids ALGSRSAGYP and WFAPPRVGYL (Table 1, entries R-15 and R-18, respectively) reproduced in Figure 2 showed the exclusion of a single amino acid (P or L) and formally of a dipeptide (YP or YL), the latter loss being far less intense. Even if $\mathrm{MS}^{3}$ experiments shown in Figure 4 showed the loss of tyrosine from both protonated truncated y-type fragment ions as discussed previously, it is difficult to exclude that this ion could also be directly produced from the protonated molecular ion by the loss of a neutral cyclic dipeptide (diketopiperazine). Moreover, when the fragment ion produced by a C-terminal neutral exclusion was very abundant ( $>50 \%$ relative abundance at least in the MS/MS spectrum), some other second generation fragmentations occurring from the protonated truncated $\left(b_{n-1}+\mathrm{H}_{2} \mathrm{O}\right)$ fragment ion were observed in few cases (Figures $2 \mathrm{~b}$ and $3 \mathrm{~b}$ ). Regarding other non-scrambled sequence ions, loss of small neutral molecules such as water and ammonia usually occurs from several fragment ions duplicating the sequence $b_{n}$ and $y_{m}$ fragment ion series. In the same manner, the production of b-type internal ions are typically triggered by a specific amino acid $(\mathrm{P}, \mathrm{R}$, or $\mathrm{H})$ but the length of the fragment is varying a lot leading to populated internal ion series as seen in Figures 2 and 3. In contrast, C-terminal exclusion of a single residue or even of a dipeptide produced few nonscrambled fragment ions indicating a very specific dissociation pathway that can be exploited for detailed sequence assignment (confirmation of trypsin miscleavage, determination of the amino acid at the $\mathrm{C}$-terminus).

\section{Conclusion}

A rather frequent peptide backbone fragmentation occurring from basic amino acid-containing free acid sequences was pointed out by screening a data set of $392 \mathrm{MS} / \mathrm{MS}$ data gathered from the collision- and laser-induced dissociation of singly charged molecular ions. Far from being an epiphenomenon, the loss of a neutral residue can be envisaged on both $\mathrm{N}$ - and C-terminal sides of the peptide chain. The $\mathrm{a}_{1}-\mathrm{y}_{\mathrm{m}-1}$ pathway led to a C-terminal $\mathrm{y}$ ion by the loss of the N-terminal residue, whereas the observed Cterminal neutral residue loss gave raise to a shortened peptide possessing the structure of a $\left(b_{n-1}+\mathrm{H}_{2} \mathrm{O}\right)$ ion. Great caution must be taken when detecting the loss of a residue from the precursor ion that represents a potent pitfall especially in de novo peptide sequencing ( $\mathrm{N}$ - versus $\mathrm{C}$ terminal amino acid determination).

\section{Acknowledgments}

The authors thank Dr. P. Verdié, Dr. L. Mouls, and Dr. N. Shenar for participating in the peptide collection elaboration.

\section{References}

1. Mann, M., Aebersold, R.: Mass spectrometry-based proteomics. Nature 422, 198-207 (2003)

2. Dongré, A.R., Jones, J.L., Somogyi, A., Wysocki, V.H.: Influence of peptide composition, gas-phase basicity and chemical modification on fragmentation efficiency: Evidence for the mobile proton model. J. Am. Soc. Mass Spectrom. 118, 8365-8374 (1996)

3. Kapp, E.A., Schutz, F., Reid, G.E., Eddes, J.S., Moritz, R.L., O'Hair, R. A., Speed, T.P., Simpson, R.J.: Mining a tandem mass spectrometry database to determine the trends and global factors influencing peptide fragmentation. Anal. Chem. 75, 6251-6264 (2003)

4. Paizs, B., Suhai, S.: Fragmentation pathways of protonated peptides. Mass Spectrom. Rev. 24, 508-548 (2005)

5. Boyd, R., Somogyi, A.: The mobile proton hypothesis in fragmentation of protonated peptides: A perspective. J. Am. Soc. Mass Spectrom. 21, 1275-1278 (2010)

6. Thorne, G.C., Ballard, K.D., Gaskell, S.J.: Metastable decomposition of peptide $[\mathrm{M}+\mathrm{H}]^{+}$ions via rearrangement involving loss of the Cterminal amino acid residue. J. Am. Soc. Mass Spectrom. 1, 249-257 (1990)

7. Gonzalez, J., Besada, V., Garay, H., Reyes, O., Padron, G., Tambara, Y., Takao, T., Shimonishi, Y.: Effect of position of a basic amino acid on C-terminal rearrangement of protonated peptides upon collisioninduced dissociation. J. Mass Spectrom. 31, 150-158 (1996)

8. Farrugia, J.M., O'Hair, R.A.J.: Involvement of salt bridges in a novel gas phase rearrangement of protonated arginine-containing dipeptides, which precedes fragmentation. Int. J. Mass Spectrom. 222, 229-242 (2003) 
9. Li, Z., Yalcin, T., Cassady, C.J.: C-terminal amino acid residue loss for deprotonated peptide ions containing glutamic acid, aspartic acid, or serine residues at the C-terminus. J. Mass Spectrom. 41, 939-949 (2006)

10. Bythell, B.J., Csonka, I.P., Suhai, S., Barofsky, D.F., Paizs, B.: Gas-phase structure and fragmentation pathways of singly protonated peptides with $\mathrm{N}$ terminal arginine. J. Phys. Chem. B 114, 15092-15105 (2010)

11. Harrisson, A.G., Young, A.B., Bleiholder, C., Suhai, S., Paizs, B.: Scrambling of sequence information in collision-induced dissociation of peptides. J. Am. Chem. Soc. 128, 10364-10365 (2006)

12. Bleiholder, C., Osburn, S., Williams, T.D., Suhai, S., Van Stipdonk, M., Harrison, A.G., Paizs, B.: Sequence-scrambling fragmentation pathways of protonated peptides. J. Am. Chem. Soc. 130, 17774-17789 (2008)

13. Erlekam, U., Bythell, B.J., Scuderi, D., Van Stipdonk, M., Paizs, B., Maître, P.: Infrared spectroscopy of fragments of protonated peptides: direct evidence for macrocyclic structures of $\mathrm{b}_{5}$ ions. J. Am. Chem. Soc. 131, 11503-11508 (2009)

14. Yu, L., Tan, Y., Tsai, Y., Goodlett, D.R., Polfer, N.C.: On the relevance of peptide sequence permutations in shotgun proteomics studies. $J$. Proteome Res. 10, 2409-2416 (2011)

15. Goloborodko, A.A., Gorshkov, M.V., Good, D.M., Zubarev, R.A.: Sequence scrambling in shotgun proteomics is negligible. J. Am. Soc. Mass Spectrom. 22, 1122-1124 (2011)

16. Chen, X., Yu, L., Steill, J.D., Oosmens, J., Polfer, N.C.: Effect of peptide fragment size on the propensity of cyclization in collisioninduced dissociation: oligoglycine $\mathrm{b}_{2}-\mathrm{b}_{8}$. J. Am. Chem. Soc. 131, 18272-18282 (2009)

17. Molesworth, S., Osburn, S., Van Stipdonk, M.J.: Influence of size on apparent scrambling of sequence during CID of b-type ions. J. Am. Soc. Mass Spectrom. 20, 2174-2181 (2009)

18. Molesworth, S., Osburn, S., Van Stipdonk, M.J.: Influence of amino acid side chains on apparent opening of cyclic $\mathrm{b}_{5}$ ions. J. Am. Soc. Mass Spectrom. 21, 1028-1036 (2010)

19. Molesworth, S., Van Stipdonk, M.J.: Apparent inhibition by arginine of macrocyclic $\mathrm{b}$ ion formation from singly charged protonated peptides. $J$. Am. Soc. Mass Spectrom. 21, 1322-1328 (2010)

20. Bythell, B.J., Knapp-Mohammady, M., Paizs, B., Harrison, A.G.: Effect of the His residue on the cyclization of b ions. J. Am. Soc. Mass Spectrom. 21, 1352-1363 (2010)

21. Saminathan, I.S., Wang, X.S., Guo, Y., Krakovska, O., Voisin, S., Hopkinson, A.C., Siu, K.W.M.: The extent and effects of peptide sequence scrambling via formation of macrocyclic $\mathrm{b}$ ions in model peptides. J. Am. Soc. Mass Spectrom. 21, 2085-2094 (2010)

22. Atik, A.E., Yalcin, T.: A systematic study of acidic peptides for b-type sequence scrambling. J. Am. Soc. Mass Spectrom. 22, 38-48 (2011)

23. Mouls, L., Aubagnac, J.-L., Martinez, J., Enjalbal, C.: Low energy Peptide fragmentations in an ESI-Q-Tof type mass spectrometer. $J$. Proteome Res. 6, 1378-1391 (2007)

24. Shenar, N., Sommerer, N., Martinez, J., Enjalbal, C.: Comparison of LID versus CID activation modes in tandem mass spectrometry of peptides. J. Mass Spectrom. 44, 621-632 (2009)

25. Dupré, M., Cantel, S., Verdié, P., Martinez, J., Enjalbal, C.: Sequencing Lys-N Proteolytic Peptides by ESI and MALDI Tandem Mass Spectrometry. J. Am. Chem. Soc. Mass Spectrom. 22, 265-279 (2011)

26. Mouls, L., Subra, G., Aubagnac, J.-L., Martinez, J., Enjalbal, C.: Tandem mass spectrometry of amidated peptides. J. Mass Spectrom. 41, 1470-1483 (2006)

27. Olsen, J.V., Ong, S.-E., Mann, M.: Trypsin cleaves exclusively Cterminal to arginine and lysine residues. Mol. Cell. Proteom. 3, 608-614 (2004)

28. Nonaka, T., Hashimoto, Y., Takio, K.: Kinetic characterization of lysine-specific metalloendopeptidases from Grifola frondose and Pleurotus ostreatus fruiting bodies. J. Biochem. 124, 157-162 (1998)

29. Hohmann, L., Sherwood, C., Eastham, A., Peterson, A., Eng, J.K., Eddes, J.S., Shteynberg, D., Martin, D.B.: Proteomic analyses using Grifola frondose metalloendoprotease Lys-N. J. Proteome. Res. 8, 1415-1422 (2009)

30. Wysocki, V.H., Tsaprailis, G., Smith, L.L., Breci, L.A.: Mobile and localized protons: a framework for understanding peptide dissociation. J. Mass Spectrom. 35, 1399-1406 (2000)

31. Bythell, B.J., Suhai, S., Somogyi, A., Paizs, B.: Proton-driven amide bond-cleavage pathways of gas-phase peptide ions lacking mobile protons. J. Am. Chem. Soc. 131, 14057-14065 (2009)
32. Tsaprailis, G., Somogyi, A., Nikolaev, E.N., Wysocki, V.H.: Refining the model for selective cleavage at acidic residues in arginine-containing protonated peptides. Int. J. Mass Spectrom. 195/196, 467-479 (2000)

33. Paizs, B., Suhai, S., Hargittai, B., Hruby, V.J., Somogyi, A.: Ab initio and MS/MS studies on protonated peptides containing basic and acidic amino acid residues: I. Solvated proton versus salt-bridged structures and the cleavage of the terminal amide bond of protonated $\mathrm{RD}^{-\mathrm{NH}_{2}}$. Int. J. Mass Spectrom. 219, 203-232 (2002)

34. Huang, Y., Wysocki, V.H., Tabb, D.L., Yates III, J.R.: The influence of histidine on cleavage $\mathrm{C}$-terminal to acidic residues in doubly protonated tryptic peptides. Int. J. Mass Spectrom. 219, 233-244 (2002)

35. Tsaprailis, G., Nair, H., Zhong, W., Kuppannan, K., Futrell, J.H., Wysocki, V.H.: A mechanistic investigation of the enhanced cleavage at histidine in the gas-phase dissociation of protonated peptides. Anal. Chem. 76, 2083-2094 (2004)

36. Tomer, K.B., Deterding, L.J., Guenat, C.: Collisionally activated dissociation spectra of sodiated peptides and peptides amides. Bio. Mass Spectrom. 20, 121-129 (1991)

37. Lin, T., Payne, A.H., Glish, G.L.: Dissociation pathways of alkalicationized peptides: opportunities for C-terminal peptide sequencing. $J$. Am. Chem. Soc. 12, 497-504 (2000)

38. Kish, M.M., Wesdemiotis, C.: Selective cleavage at internal lysine residues in protonated versus metalated peptides. Int. J. Mass Spectrom. 227, 191-203 (2003)

39. Feng, W.Y., Gronert, S., Fletcher, K.A., Warres, A., Lebrilla, C.B.: The mechanism of C-terminal fragmentations in alkali metal ion complexes of peptides. Int. J. Mass Spectrom. 222, 117-134 (2003)

40. Polce, M.J., Ren, D., Wesdemiotis, C.: Dissociation of the peptide bond in protonated peptides. J. Mass Spectrom. 35, 1391-1398 (2000)

41. Vaisar, T., Urban, J.: Probing the proline effect in CID of protonated peptides. J. Mass Spectrom. 31, 1185-1187 (1996)

42. Maux, D., Enjalbal, C., Martinez, J., Aubagnac, J.-L.: New example of a proline-induced fragmentation in ESI mass spectrometry of peptides. Rapid Commun. Mass Spectrom. 16, 1470-1475 (2002)

43. Breci, L.A., Tabb, D.L., Yates, J.R., Wysocki, V.H.: Cleavage Nterminal to proline: analysis of a database of peptide tandem mass spectra. Anal. Chem. 75, 1963-1971 (2003)

44. Unnithan, A.G., Myer, M.J., Veale, C.J., Danell, A.S.: MS/MS of protonated polyproline peptides: The influence of N-terminal protonation on dissociation. J. Am. Soc. Mass Spectrom. 18, 2198-2203 (2007)

45. Yalcin, T., Harrison, A.G.: Ion chemistry of protonated lysine derivatives. J. Mass Spectrom. 31, 1237-1243 (1996)

46. O'Hair, R.A.J.: The role of nucleophile-electrophile interactions in the unimolecular and bimolecular gas-phase ion chemistry of peptides and related systems. J. Mass Spectrom. 35, 1377-1381 (2000)

47. Farrugia, J.M., Taverner, T., O'Hair, R.A.J.: Side-chain involvement in the fragmentation reactions of protonated methyl esters of histidine and its peptides, which precedes fragmentation. Int. J. Mass Spectrom. 209, 99-112 (2001)

48. Stewart, J.M., Young, J.D.: Solid Phase Peptide Synthesis, 2nd edn. Pierce Chemical Company, Rockford, IL (1984)

49. Gu, C.; Somogyi, A.; Wysocki, V. H.; Medziihradszky, K. F. Fragmentation of protonated oligopeptides XLDVLQ $(X=L, H, K, R)$ by surface induced dissociation: additional evidence for the 'mobile proton' model. Anal. Chim. Acta. 397, 247-256 (1999)

50. Tsaprailis, G., Nair, H., Somogyi, A., Wysocki, V.H., Zhong, W., Futrell, J.H., Summerfield, S.G., Gaskell, S.J.: Influence of secondary structure on the fragmentation of protonated peptides. J. Am. Chem. Soc. 121, 5142-5154 (1999)

51. Macht, M., Asperger, A., Deininger, S.-O.: Comparison of laserinduced dissociation and high-energy collision-induced dissociation using matrix-assisted laser desorption/ionization tandem time-of-flight (MALDI-TOF/TOF) for peptide and protein identification. Rapid Commun. Mass Spectrom. 18, 2093-2105 (2004)

52. Campbell, J.M., Vestal, M.L., Blank, P.S., Stein, S.E., Epstein, J.A., Yergey, A.L.: Fragmentation of leucine enkephalin as a function of laser fluence in a MALDI TOF-TOF. J. Am. Soc. Mass Spectrom. 18, 607-616 (2007)

53. Suckau, D., Resemann, A., Schuerenberg, M., Hufnagel, P., Franzen, J., Holle, A.: A novel MALDI LIFT-TOF/TOF mass spectrometer for proteomics. Anal. Bioanal. Chem. 376, 952-965 (2003)

54. Falkner, J.A., Kachman, M., Veine, D.M., Walker, A., Strahler, J.R., Andrews, P.C.: Validated MALDI-TOF/TOF mass spectra for protein standards J. Am. Soc. Mass Spectrom. 18, 850-855 (2007) 
55. Enjalbal, C., Martinez, J., Aubagnac, J.-L.: Mass spectrometry in combinatorial chemistry. Mass Spectrom. Rev. 19, 139-161 (2000)

56. Moneti, G., Francese, S., Mastrobuoni, G., Pieraccini, G., Seraglia, R., Valitutti, G., Traldi, P.: Do collisions inside the collision cell play a relevant role in CID-LIFT experiments? J. Mass Spectrom. 42, 117-126 (2007)

57. Salek, M., Lehmann, W.D.: Neutral loss of amino acid residues from protonated peptides in collision-induced dissociation generates $\mathrm{N}$ - or Cterminal sequence ladders. J. Mass Spectrom. 38, 1143-1149 (2003)

58. Michalski, A., Cox, J., Mann, M.: More than 100,000 detectable peptide species elute in single shotgun proteomics runs but the majority is inaccessible to data-dependent LC-MS/MS. J. Proteome Res. 10, 1785$1793(2011)$

59. Ingrosso, D., Fowler, A.V., Bleibaum, J., Clarke, S.: Specificity of endoproteinase Asp-N (Pseudomonas fragi): cleavage at glutamyl residues in two proteins. Biochem. Biophys. Res. Commun. 162 1528-1534 (1989)
60. Drapeau, G.R., Boily, Y., Houmard, J.: Purification and properties of an extracellular protease of Staphylococcus aureus. J. Biol. Chem. 247, 6720-6726 (1972)

61. Neta, P., Pu, Q.-L., Kilpatrick, L., Yang, X., Stein, S.E.: Dehydration versus deamination of $\mathrm{N}$-terminal glutamine in collision-induced dissociation of protonated peptides. J. Am. Soc. Mass Spectrom. 18, 27-36 (2007)

62. Pingitore, F., Polce, M.J., Wang, P., Wesdemiotis, C., Paizs, B.: Intramolecular condensation reactions in protonated dipeptides: carbon monoxide, water, and ammonia losses in competition. J. Am. Soc. Mass Spectrom. 15, 1025-1038 (2004)

63. Khatun, J., Ramkissoon, K., Giddings, M.C.: Fragmentation characteristics of collision-induced dissociation in MALDI TOF/TOF mass spectrometry. Anal. Chem. 79, 3032-3040 (2007)

64. Rogalski, J.C., Lin, M.S., Sniatynski, M.J., Taylor, R., Youhnovski, N., Przybylski, M., Kast, J.: Statistical evaluation of electrospray tandem mass spectra for optimized peptide fragmentation. J. Am. Soc. Mass Spectrom. 16, 505-514 (2005) 